\title{
Study of the relation between Plasma Transfusion and Clinical Outcome in Critically Ill Children at Pediatric Intensive Care Unit
}

Tarek Abd El-Rahman Atiyyah, Khalid Mohamed Salah, Esraa Hassan Mohamed Hassan El-Bahrawy

Department of Pediatrics, Faculty of Medicine - Zagazig University, Zagazig, Sharkia, Egypt

*Corresponding Author: Esraa Hassan Mohamed Hassan El-Bahrawy, Mobile: (+20)01221042527,

Email: drmohamedalafandy@icloud.com

\begin{abstract}
Background: Plasma transfusions are commonly used in adult and paediatric intensive care units. Latest data showed a correlation in adult trauma patients between plasma transfusions and worse clinical results. Plasma transfusions are frequently prescribed worldwide; the indications for their use remain unclear.

Objective: To identify signs of plasma transfusions and evaluation of the impact of plasma transfusions on coagulation studies.

Patients and Methods: This prospective cohort study was conducted at the Pediatric Intensive Care unit, Zagazig University Hospital between July 2019 and January 2020. Participants in the study had a full background of sociodemographic characteristics. Total clinical examination and the seriousness of the disease was measured at admission using the Sequential Organ Failure Assessment (SOFA) score as per Ferreira 2001. Patients have been checked for critical parameters.

Results: Our analysis found that 50 percent of plasma transfusions were attributed to bleeding, 40.7 percent to hypoalbuminemia, and 9.3 percent of plasma transfusions were due to surgical conceptions. The mortality rate in our study was 25.9 percent.

Conclusion: Plasma transfusion does not have a statistical effect on mortality, but there has been little improvement in mortality over predictive SOFA mortality. Approximately ten times, no bleeding or proposed bleeding-risk operations earned plasma, based on the physician's views and conceptions. Plasma transfusion was insufficient to correct minor coagulation irregularities. Major research evaluating effective plasma transfusion techniques are desperately needed.
\end{abstract}

Keywords: Plasma transfusions, Blood component transfusion, Plasma.

\section{INTRODUCTION}

Plasma transfusions are widely prescribed in the world; the indications for their use remain uncertain. In 2011, 3,882,000 plasma units were transfused to adults and children in the United States ${ }^{(\mathbf{1})}$. According to U.S. Pediatric Health Information Administrative Records, almost $3 \%$ of all paediatric admissions reported undergo a plasma transfusion during their hospital stay ${ }^{(2)}$. Plasma administration in France has grown by more than $40 \%$ over the last 10 years, mostly in medicinal circumstances ${ }^{(3)}$.

Experts prescribe plasma transfusions especially in the form of major transfusion and in the case of bleeding consistent with reported irregular coagulation tests ${ }^{(4)}$. Observatory evidence in massively bleeding patients indicate that early use of plasma and platelets tends to be associated with better outcomes in patients with life-threatening bleeding ${ }^{(5)}$. However, in a less important therapeutic setting, adult and paediatric epidemiological trials have shown support between plasma transfusion and development of nosocomial infections (1) and acute respiratory distress syndrome ${ }^{(6,7)}$.

Therefore, it might seem necessary to decide when the benefits outweigh the side effects, particularly because previous trials have already demonstrated that plasma transfusions have not been able to fix mildly irregular coagulation tests ${ }^{(\mathbf{8}, \mathbf{9})}$. The key objectives of this research were to classify patients' characteristics for plasma transfusions, and to identify important signs of plasma transfusions.

\section{PATIENT AND METHODS}

A prospective cohort analysis was conducted at the Zagazig University Hospital in PICU between July 2019 and January 2020 including 54 seriously ill babies and children, from 1 month to 14 years of age.

Inclusion Criteria: Newborn age group and child hood (from one month to 14 years of age). Newly admitted patients to PICU with some medical or surgical reason and obtained at least one plasma transfusion.

Exclusion Criteria: Plasmapheresis patients. Patients whose age is less than 1month. Patients readmitted within 24 hours of PICU discharge. Transfusion of cryoprecipitate, albumin, or coagulation factors.

\section{Ethical and patient's approval:}

The study was approved from the Institutional Review Board (IRB), Faculty of Medicine Zagazig University. Written informal permission was received from the patients' parents to engage in the study.

Patients have been checked for critical parameters (e.g. HR, RR and temperature). Anthropometric review of all children, including weight, height and blood pressure. Sequential Company Deficiency 
Evaluation (SOFA). The SOFA score is usually determined on entry to the ICU.

The tool uses six parameters that represent the role of the organ system (respiratory, pulmonary, renal, neurological, hepatic and haematological) and gives a score of $0-4$. In cases where physiological parameters do not fit a row, zero points are given. In situations where physiological parameters are more than one row, the row containing the highest score is chosen. Regular data collection included CBC full blood count included red blood cells (RBCs), haemoglobin ( $\mathrm{Hb}$ ), hematocrit (Hct), mean corpuscular volume (MCV), mean corpuscular $\mathrm{Hb}(\mathrm{MCH})$, mean corpuscular $\mathrm{Hb}$ concentration (MCHC), white blood cells (WBC) and platelets. Serum calcium, Na, K, creatinine, urea, PT (aPTT), INR, serum albumin, bilirubin, SGOT, SGPT, and CRP are estimated.

Primary outcome: The primary result was the primary indicator for the first plasma transfusion and the coagulation tests prior to the plasma transfusion.

Secondary outcome: It was the improvements in the coagulation measurements that resulted following transfusion, namely PT, aPTT and INR.

\section{Statistical Analysis}

All data was obtained, tabulated and statistically analysed using SPSS 20.0 for Windows (SPSS Inc., Chicago, IL, USA). Quantitative data was expressed as mean \pm SD \& range. Paired test it was used to evaluate two variables based on the variable usually distributed. Wilcoxon Signed Ranks test was used to evaluate two dependent variables with non-normally distributed variables. Percent of the categorical variables is compared using the Chi-square applicable. All the experiments were two-sided. P-value $\leq 0.05$ was considered statistically significant (S) and p-value $>0.05$ was considered statistically insignificant (NS).

\section{RESULTS}

This research found that the mean age of the children surveyed was $36.8 \pm 43$ months, varying from 40 days to 168 months, 51.9 percent of which were females, and the mean weight was $13 \pm 10 \mathrm{~kg}$ (Table $1)$.

Popular reasons for admission to PICU were CNS disease ( 29.5 percent) followed by respiratory illness and organ dysfunction (24.1 percent) (Table 2).

This research found that 50 percent of plasma transfusion was due to bleeding, 40.7 percent was due to hypoalbuminemia, and 9.3 percent of plasma transfusion was due to surgical conception (Figure 1).

There was a statistically important change in INR between the patients after plasma transfusion and INR period prior to plasma transfusion $(\mathrm{p}<0.05)$. Post-hoc test identified substantial differences in INR after plasma transfusion in patients with moderate and serious bleeding $(\mathrm{p}<0.05)$ but not significantly in other categories $(\mathrm{p}=0.95)$. Post-hoc test identified a substantial difference between each INR interval prior to plasma transfusion $(\mathrm{p}<0.05)$ except for $(2.5-)$ interval and $(0.5,1.5,3.5, \geq 4.5)(\mathrm{p}>0.05)$ (Table 3).

Statistically important differences in aPTT were found between patients undergoing plasma transfusion because of plasma transfusion and aPTT period prior to plasma transfusion, $(\mathrm{p}<0.05)$. Post-hoc test identified a significant difference between hypoalbuminemia and mild bleeding $(\mathrm{p}=0.003)$. Posthoc test defined a significant difference between aPTT periods $(20-)$ and $(40-, 60-, 80-)(\mathrm{p}<0.05)$ as shown in table (4).

There was a statistically important difference between INR, aPPT and albumin before and after plasma transfusion (Figure 2).

Table (1): Patient characteristics at PICU admission, according to plasma transfusion status $(\mathrm{n}=54)$

\begin{tabular}{|c|c|c|}
\hline Variables & & \\
\hline \multicolumn{3}{|c|}{ Age Per Months } \\
\hline Mean \pm SD & \multirow{2}{*}{\multicolumn{2}{|c|}{$\begin{array}{c}36.8 \pm 43 \\
22(40 \text { davs- } 168)\end{array}$}} \\
\hline Median(range) & & \\
\hline \multicolumn{3}{|l|}{ Weight kg } \\
\hline Mean \pm SD & \multirow{2}{*}{\multicolumn{2}{|c|}{$\begin{array}{c}13 \pm 10 \\
10.5(3-60)\end{array}$}} \\
\hline Median(range) & & \\
\hline \multicolumn{3}{|l|}{ Sex } \\
\hline Boys & 26 & $48.1 \%$ \\
\hline Girls & 28 & $51.9 \%$ \\
\hline
\end{tabular}

Table (2): Frequency distribution of reasons of PICU admission $(\mathrm{n}=54)$

\begin{tabular}{||l|c|c|}
\hline \multicolumn{1}{|c|}{ Causes } & No & \% \\
\hline CNS & $\mathbf{1 6}$ & $\mathbf{2 9 . 5}$ \\
\hline Convulsion & 13 & 24.1 \\
\hline Encephalopathy & 2 & 3.7 \\
\hline Intracranial hemorrhage & 1 & 1.9 \\
\hline Respiratory infection & $\mathbf{1 3}$ & $\mathbf{2 4 . 1}$ \\
\hline Pleural effusion & 2 & 3.7 \\
\hline Bronchopneumonia & 1 & 1.9 \\
\hline Bronchiolitis & 10 & 18.5 \\
\hline Meningitis & $\mathbf{5}$ & $\mathbf{9 . 3}$ \\
\hline Septic shock & $\mathbf{1}$ & $\mathbf{1 . 9}$ \\
\hline Hemorrhagic shock & $\mathbf{1}$ & $\mathbf{1 . 9}$ \\
\hline Organs failure & $\mathbf{1 3}$ & $\mathbf{2 4 . 1}$ \\
\hline Renal & 8 & 14.8 \\
\hline Hepatic & 4 & 7.4 \\
Heart failure & 1 & 1.9 \\
\hline GE with dehydration & $\mathbf{5}$ & $\mathbf{9 . 3}$ \\
\hline
\end{tabular}


Table (3): Comparison INR change among studied patients received plasma transfusion as regard reason of plasma transfusion and INR interval before plasma transfusion $(n=54)$

\begin{tabular}{|c|c|c|c|c|c|}
\hline \multirow{2}{*}{ Item } & \multicolumn{3}{|c|}{ Change in INR after plasma transfusion } & \multirow{2}{*}{ KW } & \multirow{2}{*}{$\mathbf{P}$} \\
\hline & $\mathbf{N}$ & Mean \pm SD & Median & & \\
\hline \multicolumn{6}{|c|}{ According to reason of plasma transfusion } \\
\hline Mild bleeding* & 1 & 0.3 & 0.3000 & \multirow{5}{*}{24.5} & \multirow{5}{*}{0.0001} \\
\hline Moderate bleeding & 20 & $0.56 \pm 0.55$ & 0.4 & & \\
\hline Critical bleeding & 6 & $3.1 \pm 1.65$ & 3.2 & & \\
\hline hypoalbuminemia & 22 & $0.2 \pm 0.72$ & 0 & & \\
\hline Physician conceptions & 5 & $-0.002 \pm 0.061$ & -0 & & \\
\hline \multicolumn{6}{|c|}{ According to INR interval before plasma transfusion } \\
\hline $0.5-$ & 27 & 0.0007 & -0.01 & \multirow{5}{*}{35.2} & \multirow{5}{*}{0.0001} \\
\hline $1.5-$ & 19 & $0.57 \pm 0.47$ & 0.5 & & \\
\hline $2.5-$ & 2 & $1.5 \pm 0.71$ & 1.5 & & \\
\hline $3.5-$ & 2 & $3.02 \pm 0.03$ & 3.02 & & \\
\hline$\geq 4.5$ & 4 & $3.6 \pm 1.65$ & 3.8 & & \\
\hline
\end{tabular}

*Excluded from analysis

Table (4): Comparison aPTT change among studied patients received plasma transfusion as regard reason of plasma transfusion and aPTT interval before plasma transfusion $:(n=54)$

\begin{tabular}{|c|c|c|c|c|c|}
\hline \multirow{2}{*}{ Item } & \multicolumn{3}{|c|}{ Change in aPTT after plasma transfusion } & \multirow{2}{*}{ KW } & \multirow{2}{*}{$\mathbf{p}$} \\
\hline & $\mathbf{N}$ & Mean \pm SD & Median & & \\
\hline \multicolumn{6}{|c|}{ According to Indication of plasma transfusion } \\
\hline Mild* & 1 & 23 & 23 & \multirow{5}{*}{10.1} & \multirow{5}{*}{0.013} \\
\hline Moderate & 20 & $9.1 \pm 11.7$ & 8.5 & & \\
\hline Critical & 6 & $15.5 \pm 25.5$ & 6.5 & & \\
\hline hypoalbuminemia & 22 & $2.9 \pm 8.9$ & 0.5 & & \\
\hline Physician conceptions & 5 & $2.8 \pm 6.3$ & 1 & & \\
\hline \multicolumn{6}{|c|}{ According to aPTT interval before plasma transfusion } \\
\hline $20-$ & 26 & $0.73 \pm 4.7$ & 1 & \multirow{5}{*}{17.7} & \multirow{5}{*}{0.0001} \\
\hline $40-$ & 19 & $8.4 \pm 10.2$ & 8 & & \\
\hline $60-$ & 6 & $16.8 \pm 14.7$ & 18 & & \\
\hline $80-$ & 2 & $15 \pm 14.1$ & 15 & & \\
\hline$\geq 100^{*}$ & 1 & 66 & 66 & & \\
\hline
\end{tabular}

*Excluded from analysis 
Table (5): Comparison INR, aPPT and albumin before and after plasma transfusion of studied group as regard INR level $(n=54)$

\begin{tabular}{|c|c|c|c|c|c|}
\hline & \multirow[b]{2}{*}{ Variables } & \multicolumn{3}{|c|}{ Time } & \multirow[b]{2}{*}{$\mathbf{P}$} \\
\hline & & $\begin{array}{c}\text { Before } \\
\text { Transfusion } \\
\end{array}$ & $\begin{array}{c}\text { After } \\
\text { Transfusion } \\
\end{array}$ & $\begin{array}{c}\text { Mean } \\
\text { Difference }\end{array}$ & \\
\hline \multirow{2}{*}{$\underline{\underline{Z}}$} & $\begin{array}{l}\text { INR }<\mathbf{2}(\mathbf{n}=\mathbf{3 7}) \\
\text { Mean } \pm \text { SD } \\
\text { Median }\end{array}$ & $\begin{array}{c}1.22 \pm 0.32 \\
1.1\end{array}$ & $\begin{array}{c}1.14 \pm 0.27 \\
1.1\end{array}$ & 0.08 & $\begin{array}{c}0.055 \\
(\mathrm{NS})\end{array}$ \\
\hline & $\begin{array}{l}\text { INR } \geq \mathbf{2}(\mathbf{n}=\mathbf{1 7}) \\
\text { Mean } \pm \text { SD } \\
\text { Median }\end{array}$ & $\begin{array}{l}3.54 \pm 1.78 \\
2.4(2-7.5)\end{array}$ & $\begin{array}{c}1.69 \pm 1.19 \\
1.3\end{array}$ & 1.85 & 0.0002 \\
\hline \multirow{2}{*}{ the } & $\begin{array}{l}\text { INR }<\mathbf{2}(\mathbf{n}=\mathbf{3 7}) \\
\text { Mean } \pm \text { SD } \\
\text { Median }\end{array}$ & $\begin{array}{c}39.54 \pm 13.68 \\
34\end{array}$ & $\begin{array}{c}35.89 \pm 12.32 \\
32\end{array}$ & 3.65 & 0.031 \\
\hline & $\begin{array}{l}\text { INR } \geq \mathbf{2}(\mathbf{n}=\mathbf{1 7}) \\
\text { Mean } \pm \text { SD } \\
\text { Median }\end{array}$ & $\begin{array}{c}55.65 \pm 21.1 \\
48\end{array}$ & $\begin{array}{c}41.53 \pm 11.21 \\
37\end{array}$ & 14.12 & 0.001 \\
\hline & $\begin{array}{l}\text { Albumin } \\
\text { Mean } \pm \text { SD } \\
\text { Median } \\
\end{array}$ & $\begin{array}{c}2.2 \pm 0.56 \\
2.3 \\
\end{array}$ & $\begin{array}{c}2.4 \pm 0.56 \\
2.5 \\
\end{array}$ & 1.66 & 0.022 \\
\hline
\end{tabular}

$\mathrm{NS}=$ no significant

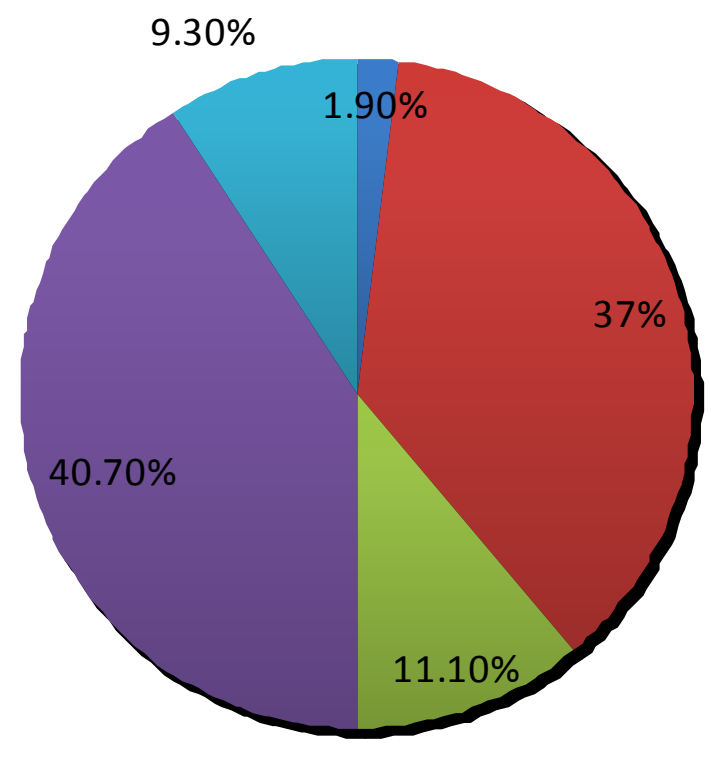
mild bleeding
moderate bleeding
critical bleeding
- Hypo albuminemia
physician conceptions

Figure (1): Percent of indications of plasma transfusion. 


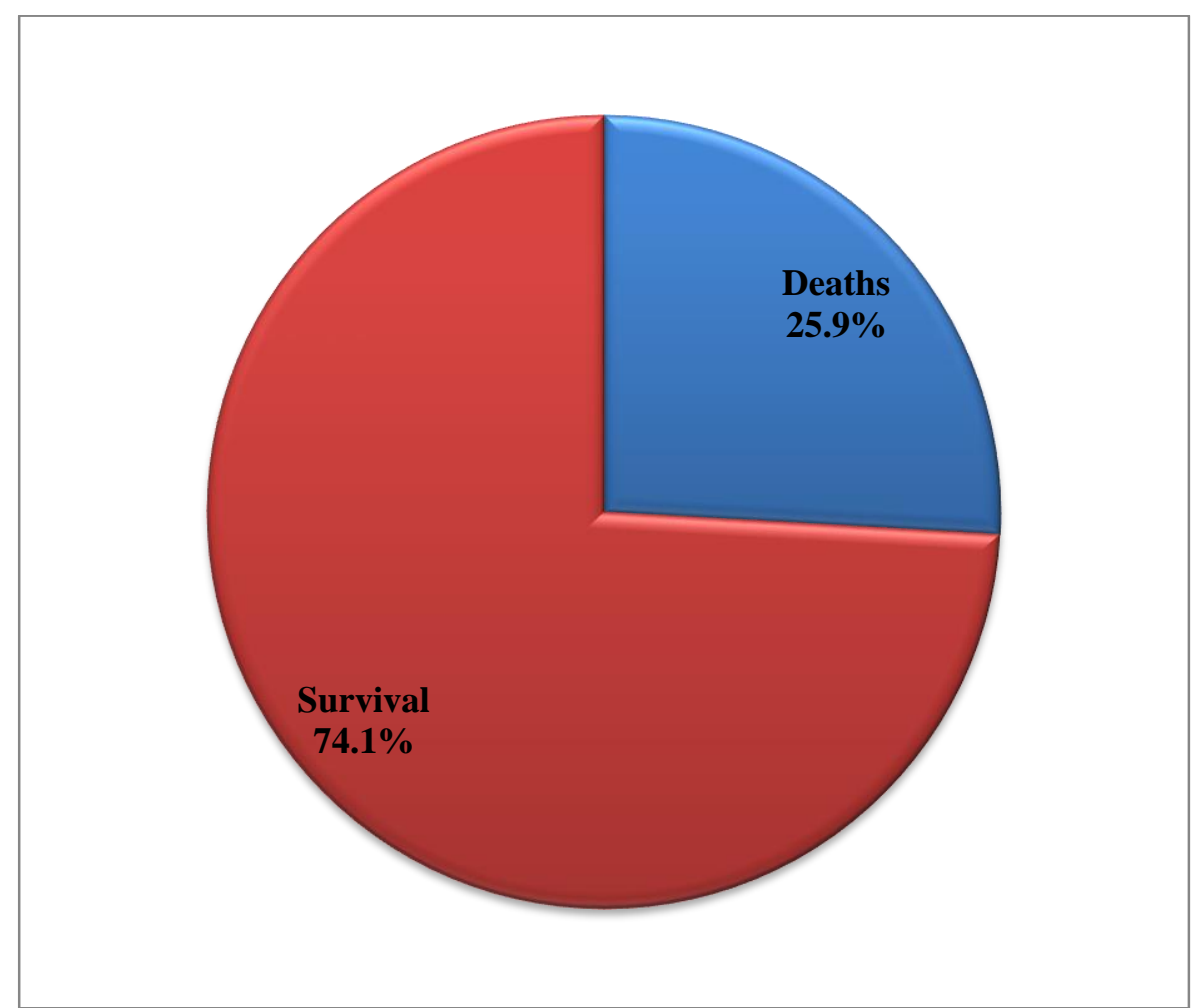

Figure (2): Percent of deaths among children admitted at PICU for plasma transfusion.

\section{DISCUSSION}

In our sample, the mean age of the children surveyed was $36.8 \pm 43$ months, ranging from 40 days to 168 months, 51.9 percent of whom were females, and the mean weight was $13.1 \mathrm{~kg}$. In comparison to our observations, Karam et al. ${ }^{(\mathbf{1 0 )}}$ study stated that the median age and weight were 1 year (IQR, 0.2-6.4) and $9.1 \mathrm{~kg}$ (IQR, 4.0-21.0) respectively. Forty-three percent of them were males. Karam et al. ${ }^{(\mathbf{1})}$ stated that their sample population contained 1 premature infant, 26 term neonates $<3$ days of age, or adults $>18$ years of age.

The present research indicated that the common reasons for admission to PICU was CNS disease (29.5\%) followed by respiratory illness and organ failure $(24.1 \%)$. This is in agreement with Bo et al. ${ }^{(\mathbf{1 1})}$ thesis under the title "The role of probiotics in the prevention of pneumonia-related ventilation in PICU. While, this is not in accordance with Karam et al. ${ }^{(10)}$ who claimed that respiratory causes were the most frequent cause of admission accompanied by heart surgery and emergency surgery. This discrepancy may be attributed to the different number of cases and plasma transfusion they received pre and post operations.

In our sample, 50 percent of the cases suggested that the plasma transfusion was either critical, moderate or minor bleeding. This is meeting with Karam et al. ${ }^{(\mathbf{1 0 )}}$ who reported that the main cause for plasma transfusion was serious bleeding in 22.3 percent of patients, moderate bleeding in 21.2 per cent, scheduled surgery or treatment in 11.7 percent, and a high risk of postoperative bleeding in 10.6 percent. No bleeding or expected operations were identified in 34.1 percent of patients. Our findings are consistent with Stanworth $\boldsymbol{e t}$ al. ${ }^{(12)}$ as they recorded that, the reason was documented as bleeding in 48 percent of episodes, 15 percent prophylaxis for the operation, and in 36 percent of cases, no procedure was scheduled and no bleeding was documented as present. Our research disagrees with the Palo et al. ${ }^{(13)}$ study, which showed that more than 6000 FFP units had been monitored in 1159 transfused patients, indicating that FFP was more frequently transfused in surgical patients, especially cardiac patients.

In our analysis, INR shift was more important when INR was > 2.5 that is in agreement with Stanworth et al. ${ }^{(14)}$ as median decreases in INR or PT were stated to be greater when the baseline pre-FFP transfusion INR or PT was higher. FFP is not effective in addressing minor changes in INR but has an effect where the INR pre-transfusion is higher. In all types of underlying medical or surgical disorders, with the exception of patients, very slight median reductions in INR were reported. Except for patients needing a reversal of warfarin coagulation. However, patients needing warfarin coagulation reversal had higher pretransfusion INRs or PTs and may also have a contribution from the administration of vitamin $\mathrm{K}$ (but not reported in this study). For non-blooded warfarin coagulation reversal patients, median reduction was1.1 (IQR,-2.8 to-0.4; $\mathrm{n}=277$ ) and median reduction was-2.1 (IQR,-3.9 to 0.9) for warfarin bleeding over coagulation reversal patients. 
Stanworth et al. ${ }^{(14)}$ observed that 31 percent of FFP therapies were in patients with no PT prolongation, and 41 percent were in patients with no bleeding and only mildly affected INR $(<2.5)$. Higher amounts of FFP were administered while the sign was bleeding (median doses: bleeding $11.1 \mathrm{ml}$ per kg, preprocedural prophylaxis $9.8 \mathrm{ml}$ per $\mathrm{kg}$, non-procedural prophylaxis $8.9 \mathrm{ml}$ per $\mathrm{kg} ; \mathrm{P}=0.009$ in groups) and when pre-transfusion INR was higher (from median dose $8.9 \mathrm{ml}$ per $\mathrm{kg}$ to INR $\leq 1.5$ to $15.7 \mathrm{ml}$ per $\mathrm{kg}$ per $\mathrm{kg})$.

Our findings are consistent with Youssef et $\boldsymbol{a l} .{ }^{(15)}$ in the analysis of the impact of FFP on laboratory variables of haemostasis, as seen by the discrepancy between the first post-transfusion results reported by INR or PT and the pre-transfusion results. The median reduction for the three classes (adults, children and infants) ranged from 0.1 to 0.2 for INR and 1.2 to 1.9 seconds for PT showing no laboratory proof of the effectiveness of the FFP transfusion.

The present research showed that there was a statistically important difference between INR, aPPT and albumin before and after plasma transfusion of studied group. Our findings are confirmed by the Karam et al. ${ }^{(10)}$ study, which stated that the median results for INR and aPTT were 1.4 (IQR, 1.2-1.7) and 41 (IQR, 33-59), respectively. The mean INR and aPTT improvements were-0.2 (IQR,-0.4 to $0 ; \mathrm{n}=281$; $\mathrm{P}, 0.001$ ) and-5 (IQR,-17 to $2 ; \mathrm{n}=356 ; \mathrm{P}, 0.001$ ) respectively. The median aPTT transition after transfusion was-2 (IQR,-7 to 3) for 249 children (62 per cent) with a baseline aPTT of less than 60 seconds and-22 (IQR,-44 to-5) for 151 children (38 percent) with baseline aPTT value of at least 60 seconds $(\mathrm{P}$, 0.0001).

Biu et al. ${ }^{(16)}$ noted that the use of FFP is not without potential danger and should be used only if indicated. Again, the existing recommendations are based on a relatively limited number of observational trials, which are primarily drawn from professional views, some of which assume that plasma contributes greatly to morbidity and mortality due to transfusion of blood components ${ }^{(\mathbf{1 7})}$.

Holcomb et al. (5) reported that thirty-day survival was improved in patients with elevated plasma: $\mathrm{RBC}$ ratio $(\geq 1: 2)$ compared to those with low plasma: $\mathrm{RBC}$ ratio $(<1: 2)$ (low: 40.4 percent vs. high: 59.6 percent, $\mathrm{P}<0.01)$. Similarly, 30 -day survival was improved in patients with high platelet: $\mathrm{RBC}$ ratio $(\geq$ 1:2) compared to low platelet: $\mathrm{RBC}$ ratio $(<1: 2)$ (low: 40.1 per cent vs. high: 59.9 per cent, $\mathrm{P}<0.01)$. The mixture of high plasma and high platelet to $\mathrm{RBC}$ ratios was correlated with reduced truncal haemorrhage, enhanced by 6-hour, one day, and one month survival, and increased intensive care unit, ventilator, and hospital-free days $(\mathrm{P}<0.05)$, with little improvement in multiple-organ failure deaths.
It is necessary to determine if the transfusion of seriously ill yet non-bleeding patients with a baseline INR of less than 2.5 is sufficient. Indeed, there could be certain advantages that are not assessed by coagulation measures. Furthermore these cuts are based on retrospective evidence and do not even illustrate the effectiveness of plasma transfusions, which should only be evaluated in a randomized controlled trial. However it seems clear that there is a more conservative co-operation in transfusion policy (18).

Limitations: Our thesis needs to be remembered. First of all, our group was a heterogeneous PICU population, and the patients that were transfused were demographically different from those who were not. Many covariates are correlated with elevated morbidity and mortality, including the seriousness of the disease at admission and the requirement for RBC transfusion. It is thus important to recognize these variables when evaluating the relationship between plasma transfusions and clinical outcomes. As the number of patients have been transfused into the first 2 days, we may consider that these patients had more radical MODS, which might justify their bad result. There may also be a tendency of 'confounding by indication,' as the prognostic factors viewed by the attending physician may affect treatment decisions. However, the regression model compensated, at least in part, for the seriousness at admission as calculated by the PRISM score as well as for the plasma transfusion prior to PICU admission.

\section{CONCLUSION}

Bleeding was the most frequent cause of plasma transfusion accompanied by hypoalbuminemia, which was suspected by physicians. Plasma transfusion does not have a statistical effect on mortality, but there has been little improvement in mortality over predictive SOFA mortality. Approximately ten times, no bleeding or proposed bleeding-risk operations earned plasma, based on the physician's views and conceptions. Plasma transfusion was insufficient to correct minor coagulation irregularities. Major research evaluating effective plasma transfusion techniques are desperately needed. The research underlines the value of introducing curriculum programs and the need for better data from potential randomized controlled trials.

\section{REFERENCES}

1. Karam O, Lacroix J, Robitaille $N$ et al. (2013): Association between plasma transfusions and clinical outcome in critically ill children: a prospective observational study. Vox Sang., 104: 342-9.

2. Puetz J, Witmer C, Huang Y et al. (2012): Widespread use of fresh frozen plasma in US children's hospitals despite limited evidence demonstrating a beneficial effect. J Pediatr., 160 (2): 210-5. 
3. Djoudi R (2013): Transfusion of plasma: productsindications (in French). Transfus Clin Biol., 20: 47-54.

4. O'Shaughnessy $\mathrm{D}$, Atterbury $\mathrm{C}$, Bolton $\mathrm{M}$ et al. (2004): British Committee for Standards in Haematology, Blood Transfusion Task Force. Guidelines for the use of fresh-frozen plasma. Cryoprecipitate and Cryosupernatant, 126: 11-28.

5. Holcomb J, Wade C, Michalek J et al. (2008): Increased plasma and platelet to red blood cell ratios improves outcome in 466 massively transfused civilian trauma patients. Ann Surg., 248: 447-58.

6. Dara S, Rana R, Afessa B et al. (2005): Fresh frozen plasma transfusion in critically ill medical patients with coagulopathy. Indian J Crit Care Med., 33 (11): 2667-71.

7. Watson G, Sperry J, Rosengart $M$ et al. (2009): Fresh frozen plasma is independently associated with a higher risk of multiple organ failure and acute respiratory distress syndrome. J Trauma Acute Care Surg., 67 (2): 221-30.

8. Church G, Matthay M, Liu K et al. (2009): Blood product transfusions and clinical outcomes in pediatric patients with acute lung injury. Pediatr Crit Care Med., 10: 297-302.

9. Abdel-Wahab O, Healy B, Dzik W (2006): Effect of fresh-frozen plasma transfusion on prothrombin time and bleeding in patients with mild coagulation abnormalities. Transfusion, 46: 1279-85.

10. Karam O, Demaret $P$, Shefler A et al. (2015): Indications and effects of plasma transfusions in critically ill children. Am J Respir Crit Care Med., 191 (12): 13951402 .
11. Bo L, Li J, Tao T et al. (2014): Probiotics for preventing ventilator-associated pneumonia. Cochrane Database Syst Rev., 10: 25-29.

12. Stanworth S, Grant $\square$ Casey J, Lowe D et al. (2011): The use of fresh-frozen plasma in England: high levels of inappropriate use in adults and children. Transfusion, 51 (1): 62-70.

13. Palo R, Capraro L, Hovilehto $\mathrm{S}$ et al. (2006): Population-based audit of fresh frozen plasma transfusion practices. Transfusion, 4: 1921-5.

14. Stanworth S, Walsh T, Prescott $R$ et al. (2011): A national study of plasma use in critical care: clinical indications, dose and effect on prothrombin time. Critical care, 15 (2): R108.

15. Youssef W, Salazar F, Dasarathy S et al. (2003): Role of fresh frozen plasma infusion in correction of coagulopathy of chronic liver disease: a dual phase study. Am J Gastroenterol., 98: 1391-4.

16. Biu E, Beraj S, Vyshka G et al. (2018): Transfusion of fresh frozen plasma in critically ill patients: effective or useless? Open access Macedonian J Med Sci., 6 (5): 82025.

17. Alcorn K, Ramsey G, Souers $R$ et al. (2017): Appropriateness of plasma transfusion: a College of American Pathologists Q-Probes Study of guidelines, waste, and serious adverse events. Arch Pathol Lab Med., 141 (3): 396-401.

18. Williamson L, Devine D (2013): Challenges in the management of the blood supply. Lancet, 381: 1866-75. 